\title{
GraduAL E NÃo LINEAR: A AFIRMAÇÃO DOS DiREITOS HuMANOS NO MUNDO
}

\author{
MONDAINI, Marco \\ Direitos humanos. \\ São Paulo: Contexto, 2008.
}

\section{POR}

\section{Tiago Eloy Zaidan ${ }^{1}$}

4 m 2008 comemorou-se 60 anos da Declaração Universal dos Direitos Humanos, importante marco universalizador que coroou a militância dos direitos humanos do pós-Segunda Guerra Mundial. Contudo, a marcha dos direitos humanos na lida por sua afirmação é bem anterior à saliente seção da Assembléia Geral das Nações Unidas, realizada em 10 de dezembro de 1948. Trata-se, na verdade, de uma labuta que ultrapassou séculos, modos de produções divergentes e que se banhou de sangue em diversos momentos revolucionários.

Lançado em 2006, o livro Direitos bumanos, do historiador Marco Mondaini, apresenta-se pertinente, por reunir 50 escritos, de diversas datas e naturezas, selecionados por terem cumprido um importante papel na afirmação dos direitos humanos em sua jornada mundial, ao longo da história moderna e contemporânea. Dentre tais escritos estão, ora por meio de trechos, ora por meio

\footnotetext{
${ }^{1}$ Mestre em Comunicação Social pela Universidade Federal de Pernambuco e pesquisador do Grupo de Pesquisa COMULTI - UFAL/ COS/ CNPq. End. eletrônico: eloyzaidan@gmail.com
} 
de transcrições integrais, cartas de direitos, hinos, discursos, encíclicas da igreja Católica, e obras relevantes de grandes vultos do pensamento social universal, como Rousseau, Locke, Montesquieu, Stuart Mill e Marx, dentre outros.

Mondaini é mestre em história econômica pela Universidade de São Paulo (USP), doutor em serviço social pela Universidade Federal do Rio de Janeiro (UFRJ) e professor do departamento de Serviço Social da Universidade Federal de Pernambuco (UFPE). Sua militância intelectual em defesa da afirmação dos direitos humanos, já reconhecida nacionalmente, vem pautando sua carreira acadêmica. Defesa esta justificada por teses como a que atribui “... o nível de civilidade alcançado por uma sociedade - e seu progressivo distanciamento da barbárie...” à "... capacidade que esta tem de fazer com que os seus concidadãos sejam protegidos pelo generoso guarda-chuva dos direitos humanos" (MONDAINI, 2008, p.12).

\section{A BURGUESIA COMO VANGUARDA}

0 primeiro ciclo de afirmação dos direitos humanos na história mundial ocorre, ao longo dos séculos XVII e XVIII, com o paulatino advento de um novo modo de produção hegemônico, o capitalismo, em superação ao feudalismo, e com a ascensão de uma nova classe social: a burguesia. Pode-se dizer que sua origem remonta a Inglaterra, Estados Unidos e França.

Em seu bojo está a luta pelo reconhecimento dos direitos civis e políticos, possibilitando, para um segundo momento, a ampliação do relevo inicial, para contemplar direitos no sentido das liberdades coletivas e, principalmente, da igualdade política, com a labuta pelo sufrágio universal.

Há também uma transformação significativa na sociedade, antes rural e agrícola, passando à urbana e industrial. Tais modificações não ocorreram em meio à contínua serenidade. As chamadas revoluções burguesas permearam as mudanças, minando o poder monárquico absoluto em favor de uma desconcentração dos poderes estatais.

Intelectualmente, o período de transição foi marcado, da mesma forma, pela superação e antigas idéias em detrimento de novas concepções. As revoluções burguesas nutriam-se do pensamento iluminista, que, ao contrário da visão teológica da vida, defendia de modo basilar o uso da razão como meio de se conhecer o mundo. 


\section{OS DIREITOS HUMANOS NA PÓS-REVOLUÇÃO FRANCESA}

A afirmação dos direitos humanos já havia dados os primeiros passos, todavia, é com a Revolução Francesa (1789), ainda incluída no primeiro ciclo da jornada dos direitos humanos no mundo, que tais ideais se expandem. Não só isso. Por meio desse processo revolucionário entram em cena diversos posicionamentos e lideranças políticas distintas: dos posicionamentos políticos reacionários aos revolucionários extremados, passando pelos conservadores e pelos revolucionários moderados.

No tocante aos direitos civis e políticos, tal período, iniciado em 1789, não seguiu um caminho único e absoluto. Houve, notadamente, ondas de estagnações e recuos ao passo em que também ocorreram avanços em dados momentos. Progressos e retrocessos estes sempre ligados à intensidade das pressões exercidas pelos movimentos dos trabalhadores, o que acabava por exigir da burguesia um posicionamento. A obra Direitos Humanos destaca que o pensamento liberal também precisou dialogar com três correntes político-ideológicas distintas, em disputa entre si pela hegemonia na construção do mundo contemporâneo que surgia com as revoluções burguesas. São elas: a democracia, o socialismo e 0 nacionalismo (MONDAINI, 2008, p. 64). Tudo isso em meio a ações violentas de aniquilamento das forças remanescentes do regime feudal, gradualmente superado pelo capitalismo avassalador.

\section{A luta dos trabalhadores E O PARAdOXo DO SOCIALISMO “REAL"}

0 segundo ciclo de afirmação dos direitos humanos é fortemente influenciado por uma luta entre classes então relativamente novas, a burguesia - a esta altura já assumindo um papel reacionário - e os trabalhadores. Nesse período, o pensamento socialista e as ações inspiradas por este, possuindo em sua essência a crítica à lógica da produção e reprodução da desigualdade no capitalismo, passa a vincular-se, intensamente, com as lutas em defesa dos direitos humanos.

O socialismo trata-se de um ideário que, tendo por objetivo a transformação da realidade capitalista, expande-se, principalmente após a onda revolucionária da Primavera dos Povos, encetada a partir de 1848 no continente europeu. Intelectualmente, coube ao filósofo alemão Karl Marx o exame das entranhas 
contraditórias do capitalismo, inspirando - direta ou indiretamente - a maior parte dos processos de revolução socialistas ocorridas pelo mundo ao longo dos séculos XIX e XX, inclusive aquelas vitoriosas: Rússia (1917), China (1949) e Cuba (1959). Nestas sociedades, todavia, ao passo em que se protagonizou a ascensão dos direitos sociais ao patamar de direitos fundamentais de todos os indivíduos, assistiu-se a marginalização dos direitos civis e políticos.

Com o paulatino avanço do socialismo pelo mundo, sobretudo no pósguerra, os países capitalistas passaram a estender os seus direitos e garantias sociais como forma de se contrapor à sedução socialista entre as camadas subalternas da sociedade. Era o advento da experiência do "Estado de bem-estar social".

\section{LUTAS POR NOVAS E VELHAS DEMANDAS}

0 terceiro ciclo da afirmação dos direitos humanos no mundo é marcado por uma luta dupla: em defesa da efetiva realização de direitos já conquistados em momentos anteriores, mas ainda não estendido a todos na prática, e da ampliação do hall de direitos, com a inclusão de novas demandas a se somarem às conquistas já obtidas. Daí o erguimento e o desconforto com a notória exclusão de setores da sociedade por parte das práticas efetivas dos direitos humanos. Dentre tais despojados, encontram-se não apenas as minorias como também maiorias que, a despeito de seu suposto poder dentro de uma democracia, permaneciam sem voz e sem o respaldo que deveria ser fornecido pelo "guarda-chuva" dos direitos humanos. Como exemplos de tal situação, podem ser citados os negros, as mulheres, os homossexuais, os loucos - tão bem retratados por Foucault em seu História da loucura na idade clássica -, dentre outros.

Marco Mondaini (2008, p. 141-142) chega a observar que, para além da ausência de concretização efetiva de vários elementos dos direitos humanos relativos a tais setores tradicionalmente marginalizados da sociedade, havia casos extremos de nações que, até meados da década de 1950, sequer haviam municiado suas cartas jurídico-formais com promessas de direitos para parte ou totalidade dos setores classicamente desprestigiados da sociedade.

Também se remete a este ciclo, mais especificamente nos anos posteriores à Segunda Guerra Mundial, a contundente expressão de contrariedade com relação às mortíferas guerras, imposições e avanços imperialistas e revoluções que varreram a humanidade até então, inspirando reflexões ético-filosóficas a respeito 
do homem como espécie social e sua ameaçadora sede desencadeada pela busca do poder político e econômico.

Como fator positivo acentuado do terceiro ciclo nota-se o advento de novos movimentos dedicados à guarida de novas e não menos importantes demandas. Destaque para as lutas ambientalistas, pacifistas - pungentes, sobretudo, após as duas grandes guerras mundiais que assolaram o século XX - e, principalmente, as lutas contra as ações criminosas de Estados despóticos contra setores de sua própria população. Com esta última luta, bastante presente nos últimos 25 anos do século XX, dá-se a consolidação dos chamados "direitos dos povos", que visa proteger a dignidade e a vida de grupos perseguidos, e a incorporação do conceito de crime contra a humanidade, que caracteriza as ações de perseguição e extermínio motivadas por questões como etnia, profissão religiosa, etc., como uma afronta não apenas aos membros do grupo perseguido, mas também a todos os homens e mulheres do planeta.

\section{CONSIDERAÇÕES FINAIS}

Embora a tradição dos direitos humanos continue se afirmando, por meio de conquistas (não lineares - é sempre bom frisar), não são poucos aqueles que fazem oposição a ela, ou, quando não, encaram-na com relativa desconfiança. Neste bojo, como bem cita Mondaini (2008, p. 12) em seu Direitos Humanos, estão: os neoliberais, que a vêem como um fardo a atrapalhar os seus objetivos de lucro racional, via livre-mercado; os militantes marxistas ortodoxos, que a vêem como mera colcha mal-retalhada com vistas a, apenas, encobrir as estruturas e lutas de classes na contraditória sociedade capitalista; e, ainda, a generalizada e ordinária visão que rotula os direitos humanos como mero instrumento de defesa de "bandidos".

Não deixa de ser curioso como a militância a favor dos direitos humanos possa causar tanta repugnância e suspeita, sentimentos que não são exclusividade do séculoXXI. Em sua jornada o que mudou foram os seus opositores: representantes da nobreza e do clero, durante o regime feudal, colonizadores europeus, no advento da modernidade, e até mesmo um ex-aliado importante, a burguesia, com o avanço da sociedade capitalista e a sua posterior consolidação. No século XX, já eram tantos os opositores de vários segmentos ideológicos distintos, que se tornou uma missão inglória lhes atribuir o crédito devido. 
A despeito de tanto aferro, para Mondaini, os direitos humanos possuem um sentido universal, “... antes de mais nada, porque passou a tratar a totalidade dos seres humanos vivos com base em critérios igualitários...” (2008, p. 12), percepção esta, complementada pela tradição que prega o tratamento dos desiguais de maneira desigual. Explica-se: para aqueles indivíduos inferiorizados no interior das relações sociais, faz-se imperativo um tratamento legal distinto, com vistas a alçar-lhe à condição de par dos demais indivíduos. Somente assim a igualdade puramente formal passaria a ter cabimento. 